\title{
Association between cellular radiosensitivity and G1/G2 checkpoint proficiencies in human cholangiocarcinoma cell lines
}

\author{
ARUNEE HEMATULIN ${ }^{1}$, DANIEL SAGAN ${ }^{2}$, KANLAYANEE SAWANYAWISUTH ${ }^{3,5}$, \\ WUNCHANA SEUBWAI $^{4,5}$ and SOPIT WONGKHAM ${ }^{3,5}$
}

\author{
${ }^{1}$ Radiobiology Research Laboratory, Department of Radiation Technology, Faculty of Allied Health Science, \\ Naresuan University, Phitsanulok 65000, Thailand; ${ }^{2}$ Independent Researcher, D-93051 Regensburg, Germany; \\ ${ }^{3}$ Department of Biochemistry, ${ }^{4}$ Department of Forensic Science, Faculty of Medicine, ${ }^{5}$ Liver Fluke and \\ Cholangiocarcinoma Research Center, Khon Kaen University, Khon Kaen 40002, Thailand
}

Received February 20, 2014; Accepted June 2, 2014

DOI: 10.3892/ijo.2014.2520

\begin{abstract}
Cholangiocarcinoma is a destructive malignancy with a poor prognosis and lack of effective medical treatment. Radiotherapy is an alternative treatment for patients with unresectable cholangiocarcinoma. However, there are limited data on the radiation responsiveness of individual cholangiocarcinoma cells, which is a key factor that influences radiation treatment outcome. In this study, we found that cholangiocarcinoma cell lines differ remarkably in their radiosensitivity. The variation of radiosensitivity of cholangiocarcinoma cells correlates with their p53 status and existing G1 and/or G2 checkpoint defects. We also demonstrated the potential of checkpoint kinase Chk1/2 inhibition on the enhancement of the radiosensitivity of cholangiocarcinoma cells. Thus, this study provides useful information for predicting radiation response and provides evidence for the enchantment of radiotherapeutic efficiency by targeting checkpoint kinase Chk1/2 in some subpopulations of cholangiocarcinoma patients.
\end{abstract}

\section{Introduction}

Cholangiocarcinoma (CCA) is a lethal malignancy that originates from the biliary epithelium. The worldwide incidence of CCA is relatively rare but the incidence and mortality have both gradually increased over the past decades (1-4). CCA

Correspondence to: Professor Sopit Wongkham, Department of Biochemistry, Faculty of Medicine, Khon Kaen University, Khonkaen 40002, Thailand

E-mail: sopit@kku.ac.th

Dr Arunee Hematulin, Department of Radiation Technology, Faculty of Allied Health Science, Naresuan University, Phitsanulok 65000, Thailand

E-mail: aruneeh@nu.ac.th; hematulin_a@yahoo.com

Key words: cholangiocarcinoma, radiotherapy, cell cycle checkpoint, Chk1/2 inhibition is an aggressive cancer, with a poor survival rate and lack of effective medical treatment $(4,5)$. Up to date, surgical resection is the only potentially curative treatment for CCA, nevertheless, the 5-year survival rate is dismal (6-8). In addition, the majority of CCA patients presents at an advanced stage when surgical therapy is not feasible $(5,9,10)$.

Chemotherapy is considered as a reasonable treatment option for unresectable and advanced CCA (9). However, the clinical benefit of this treatment regime is very low due to remarkably resistant of CCA to common chemotherapy $(6,9)$. The use of several chemotherapeutic drugs such as gemcitabine, cisplatine, leucovorrin-mediated 5-fluorouracil or capectabine has been considered as the active regimens in CCA (11-13). Nevertheless, neither single drug nor combination treatment has prolonged the median survival time to exceed 12 months (14).

Radiotherapy is regarded as an alternative therapy for patients with unresectable CCA and as an adjuvant or neoadjuvant treatment (15-20). Most studies have demonstrated the benefit of radiotherapy in terms of survival outcomes. However, the efficacy of this modality remains very low due to the resistance of CCA cells to the fatal effects of radiation. The responsiveness of cancer cells to radiotherapy is influenced by many factors. This includes such biologic factors as intrinsic radiosensitivity, proliferation status, and genetic alterations in DNA damage checkpoints, DNA repair and cell death pathways (21-24).

The DNA damage checkpoints are cardinal factors in response to radiation-induced DNA damage or DNA damaging chemotherapy. The function of these checkpoints is to facilitate DNA repair and promote cell death in unrepaired cells (25). Most cancer cells encompass multiple defects in DNA damage checkpoints and cell death pathways leading to resistance to radiation-induced cell death (26). Cancer cells with a defect in G1 checkpoint depend on S and G2 checkpoints to repair radiation-induced DNA damage (27). Since cells with damaged DNA can only be transiently arrested in the $S$ phase, G2 checkpoints are key guardians to prevent these cells from attempting the complex process of mitosis (25). It has been proposed that abrogation of $\mathrm{G} 2$ checkpoints in cancer cells 
could prevent completion of DNA repair. Therefore, cancer cells with damaged DNA are forced to enter the $M$ phase and subsequently die while attempting to divide $(27,28)$.

Enhancing radioresponsiveness of tumors by using checkpoint kinase inhibitors is theoretically a promising approach to increase efficacy of radiotherapy (29). Thus, several studies have analyzed the effects of combined applications of checkpoint kinase inhibitors and ionizing radiation (30-33). Nevertheless, the enhancement of radioresponsiveness of CCA cells by checkpoint kinase inhibitors has not been investigated.

In this study, we examined the efficiency of G1 and G2 checkpoints of three human CCA cell lines: KKU-100, KKU-M214, and KKU-M055 and correlated existing G1 and/or G2 checkpoint defects with the radiosensitivity of CCA cell lines. Furthermore, we evaluated the potential of checkpoint kinase Chk1/2 inhibition to enhance the radiosensitivity of CCA cell lines. Thus, this study provides useful information for improving radiotherapeutic outcome of CCA patients.

\section{Materials and methods}

Cell culture. The human CCA cell lines established from primary tumor of CCA patients with different histological types: KKU-100 and KKU-M055 (poorly differentiated adenocarcinoma), and KKU-M214 (moderately differentiated adenocarcinoma) were obtained from the Liver Fluke and Cholangiocarcinoma Research Center, Khon Kaen University. MMNK1, an immortalized human cholangiocyte cell line was a gift from Dr N. Kobayashi (34). Cells were cultured at $37^{\circ} \mathrm{C}$, $5 \% \mathrm{CO}_{2}$ in DMEM/F12, containing $2.5 \mathrm{mM}$ L-glutamine, $10 \%$ fetal bovine serum, $0.25 \%$ sodium bicarbonate, $40 \mathrm{U} / \mathrm{ml}$ penicillin $\mathrm{G}$ and $40 \mu \mathrm{g} / \mathrm{ml}$ streptomycin.

Cell irradiation and treatments. Approximately $5 \times 10^{4}$ cells/well of exponentially growing cells were seeded into 6-well plates. Cells were irradiated at room temperature with a single dose of $0,2,4$ or $6 \mathrm{~Gy}$ at a dose rate of $2.2 \mathrm{~Gy} /$ min (Cobalt-60 source; Theratron Phoenix). The source to sample distance was $80 \mathrm{~cm}$. After irradiation, cells were incubated at $37^{\circ} \mathrm{C}$ in a $5 \% \mathrm{CO}_{2}$ humidified atmosphere. For G1 checkpoint analyses, the cells were cultivated with growth medium containing $10 \%$ fetal bovine serum for $12 \mathrm{~h}$. Then, the cells were washed with PBS, cultivated in serum-free medium for $24 \mathrm{~h}$ and irradiated with a single dose of $6 \mathrm{~Gy}$. Subsequently, cells were released from starvation by replacement the medium with fresh growth medium containing $10 \%$ fetal bovine serum. The cells were collected at different time points for further analysis. For G2 checkpoint, CCA cells were gamma-irradiated with a single dose of $6 \mathrm{~Gy}$ and subsequently, the irradiated cells were collected at different time points for cell cycle and western blot analysis. For checkpoint kinase inhibitor treatment, cells were treated with 50 or $100 \mathrm{nM}$ of 1-(2-((S)-piperidin-3-ylcarbamoyl)5-(3-fluorophenyl)thiophen-3-yl) urea (AZD7762) (Selleck Chemicals, USA) for $2 \mathrm{~h}$. Then, the cells were irradiated with a single dose of 2, 4 or $6 \mathrm{~Gy}$, and were collected at different time points for further analysis.

Clonogenic cell survival assays. Cells were seeded in duplicate into a 6-well plate. The cell number seeded per plate varied with the radiation dose, so that colonies could be counted conveniently. The cells were irradiated with a single dose of $0,2,4$ or $6 \mathrm{~Gy}$. The cells were allowed to grow for 10-14 days until the surviving cells produced macroscopically visible colonies. The cells were fixed with $95 \%$ ethanol for $10 \mathrm{~min}$ and then stained with Giemsa for $10 \mathrm{~min}$. Colonies containing more than 50 cells were counted, and survival fractions were calculated as ratios of the amount of colonies formed from treated cells and untreated cells, corrected for plating efficiency.

Cell cycle analysis. Approximately $8 \times 10^{4}$ cells/well were seeded into a 6-well plate and cultivated for $12 \mathrm{~h}$. Two hours prior to irradiation, the cells were treated with or without 50 or $100 \mathrm{nM}$ of AZD7762. The treated cells were irradiated with a single dose of $6 \mathrm{~Gy}$ and collected $24 \mathrm{~h}$ after irradiation. Propidium iodide (PI) staining of isolated nuclei for cell cycle analysis was performed as described previously (35). Briefly, the cell pellet was mildly resuspended in a solution containing $584 \mu \mathrm{g} / \mathrm{ml} \mathrm{NaCl}, 1,000 \mu \mathrm{g} / \mathrm{ml} \mathrm{Na}$-citrate, $10 \mu \mathrm{g} / \mathrm{ml}$ RNase A, $0.3 \mu \mathrm{g} / \mathrm{ml}$ Nonidet P-40 and $50 \mu \mathrm{g} / \mathrm{ml}$ PI. The cell suspensions were incubated for $30 \mathrm{~min}$ in the dark at room temperature, followed by the addition of a solution containing $15 \mathrm{mg} / \mathrm{ml}$ citric acid, $0.25 \mathrm{mM}$ sucrose and $50 \mu \mathrm{g} / \mathrm{ml}$ PI. The suspension of PI-stained isolated nuclei was analyzed with a FACScan (Becton-Dickinson) flow cytometer.

Terminal deoxynucleotidyltransferase dUTP nick end labeling (TUNEL) assay. Cells were seeded onto sterile glass cover slips and cultured in 6-well plates overnight. The cells were treated with $100 \mathrm{nM} \mu \mathrm{g} / \mathrm{ml}$ of AZD7762 or 6 Gy of gamma-irradiation alone or with a combination of both treatments. Forty-eight hours after irradiation, a TUNEL assay was performed according to the manufacturer's protocol (Click-iT ${ }^{\circledR}$ TUNEL Alexa Fluor ${ }^{\circledR} 647$ Imaging Assay, Invitrogen). The stained cells were visualized under fluorescent microscope. For each treatment condition, the number of TUNEL-positive stained cells was counted from 30 randomly selected fields and expressed as percentage of the total number of nucleated cells.

Western blot analysis. Total protein was extracted from cells at indicated time points after each treatment as described (35). A total of $30 \mu \mathrm{g}$ of protein from each sample were separated by SDS-polyacrylamide gels electrophoresis and electro-blotted onto PVDF membranes. The membranes were blocked in TBS-T containing 5\% non-fat skim milk for $1 \mathrm{~h}$ at room temperature. Then, the membranes were probed with a primary antibody diluted in 3\% BSA in TBS-T overnight at $4^{\circ} \mathrm{C}$. After washing thrice with TBS-T, the membranes were incubated with a horseradish peroxidase-labeled secondary antibody diluted in blocking buffer for $1 \mathrm{~h}$. The membranes were washed thrice with TBS-T and the immunoreactivity was detected by chemiluminescence (GE Healthcare, Buckinghamshire, UK) on X-ray film.

Statistical analyses. Data are shown as the mean \pm SD or SE of three independent experiments. For survival analysis, survival fractions $S F$ were normalized to the survival observed in the treatment groups that received no irradiation. Survival curves 


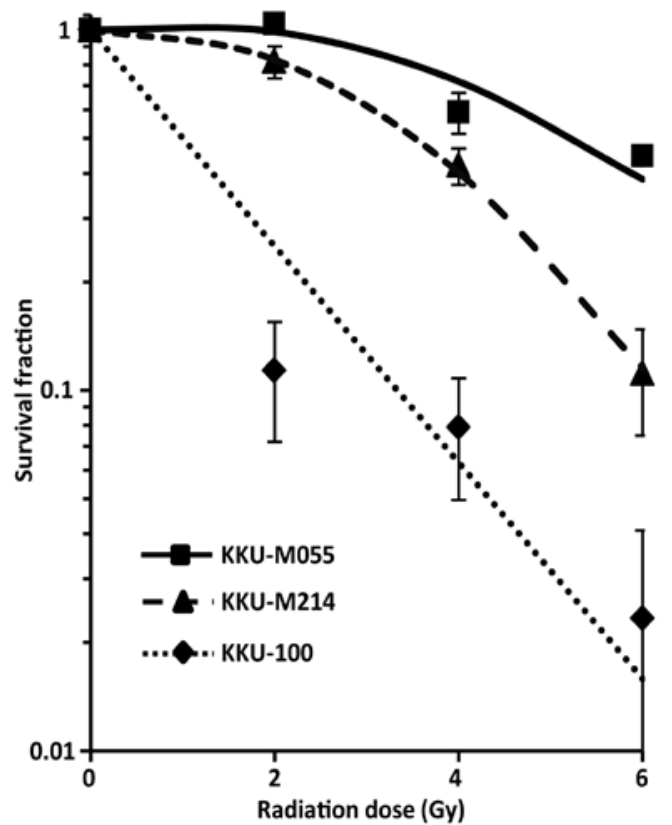

Figure 1. Cellular radiosensitivity of human cholangiocarcinoma cells; KKU-100 (diamond), KKU-M055 (rectangle) and KKU-M214 (triangle). Cells were seeded into 6 -well plates and then irradiated with a single dose of $0,2,4$ or $6 \mathrm{~Gy}$ of gamma-radiation at room temperature. Clonogenic survival of gammairradiated cells was determined twelve days later. The plot shows the mean surviving fractions \pm standard deviation from three independent experiments.

were fitted to a linear quadratic model of the form $S F=e^{-\alpha d-\beta d^{2}}$ for the cell lines KKU-M214 and KKU-M055, where $d$ is the radiation dose and $\alpha$ and $\beta$ are constants. Survival of the cell line KKU-100 was fitted to a linear model of the form $S F=e^{-\alpha d} . \mathrm{D}_{37}$ values were calculated from three independent experiments and tested for significant differences by ANOVA analysis followed by Tukey's post hoc testing.

\section{Results}

Human CCA cells possess different radiosensitivities. We first assessed the radiosensitivity of each CCA cell line. Clonogenic survival assays were performed after gamma irradiated with the dose rate of $2.2 \mathrm{~Gy} / \mathrm{min}$. Cell survival curves were plotted and the $\mathrm{D}_{37}$ values were calculated. As shown in Fig. 1, the radiosensitivity of CCA cell lines varied from the most radiosensitive to the most radioresistant cell lines KKU-100 >KKU-M214 >KKU-M055 with the $\mathrm{D}_{37}$ values of $1.5 \pm 0.2,4.2 \pm 0.2$ and $6.1 \pm 0.2 \mathrm{~Gy}$, respectively.
P53 status of the human CCA cells in response to radiation damage. As the accumulation of p53 protein following irradiation is an important determinant of cellular radiosensitivity, we further determined p53 levels of each cell line after exposure to radiation. The levels of p53 proteins in CCA cell lines observed as full length in KKU-100 or truncated as observed in KKU-M214 and KKU-M055 and the non-cancerous MMNK1 cell were increased with time of irradiation (Fig. 2). The levels of p53 protein were significantly lower in all CCA cell lines as compared to that of the immortalized cholangiocyte MMNK1 cells.

Radiation-induced apoptosis in human CCA cells. Apoptosis is a common mechanism of cell death in tumors induced by ionizing radiation. Therefore, apoptosis induction in CCA cell lines was determined in this study (Fig. 3). In the most radiosensitive cell line (KKU-100), apoptosis was strongly induced from $0.37 \%$ apoptotic cells in the control cultures to $23.40 \%$ in the irradiated cell cultures at $48 \mathrm{~h}$ after irradiation. Apoptosis induction in KKU-M214 cell line was moderate. The amount of apoptotic cells increased from 2.14 to $9.15 \%$. Remarkably, radiation increased the amount of apoptotic cells only slightly from 0.71 to $1.43 \%$ in KKU-M055 cells, which is the most radioresistant cell line.

G1 checkpoint is defective in radioresistant CCA cells. To assess whether CCA cell lines had a defect in G1 checkpoint, the cells were synchronized at early G1 phase by serum deprivation, then were irradiated and released from starvation as described in Materials and methods. Representative results of cell cycle analyses are shown in Fig. 4A. After release from serum starvation, the proportions of the cells in $\mathrm{S}$ phase were significantly increased in all CCA cell lines as observed at $24 \mathrm{~h}$ then declined to nearly basal level within $48 \mathrm{~h}$. However, in the cells that were irradiated prior to release from serum starvation, only KKU-100 cells were persisted at the G1 phase while KKU-M214 and KKU-M055 cells entered $\mathrm{S}$ and $\mathrm{G} 2 / \mathrm{M}$ phase dramatically. These results indicate that G1 checkpoint was effective in KKU-100 cells, but defective in M055 and KKU-M214 cells. The observations were further underlined by detection of proteins involved in the cell cycle and checkpoint control during G1/S transition. As shown in Fig. 4B, after release from serum starvation, levels of pRb-Ser795, pRb-Ser807/811, cdc25A and cyclin A were clearly induced in all unirradiated CCA cells. Remarkably, these proteins were not induced in KKU-100 cells that were irradiated prior to release from

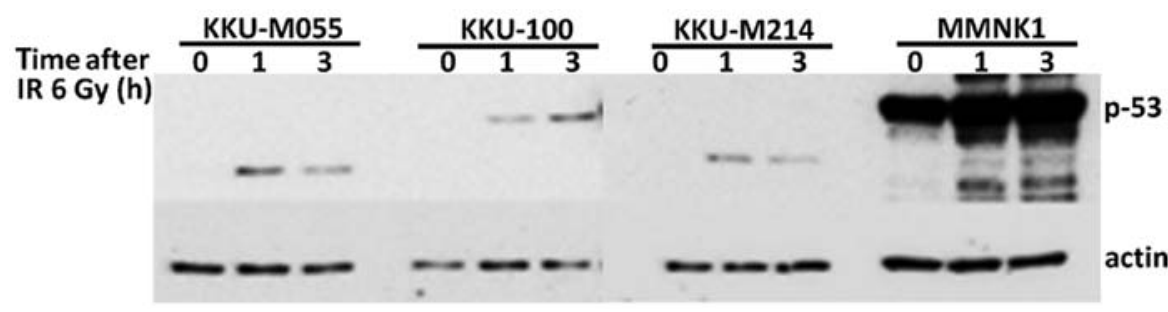

Figure 2. P-53 status of human cholangiocarcinoma cells in response to radiation damage. Gamma-irradiated cells were collected at different time points for total cell lysates extraction. The levels of p-53 protein in human cholangiocarcinoma cell lines (KKU-100, KKU-M055, KKU-M214) and an immortalized human cholangiocyte cell line (MMNK1) were determined by western blot analysis. Detection of actin was used as a loading control. 

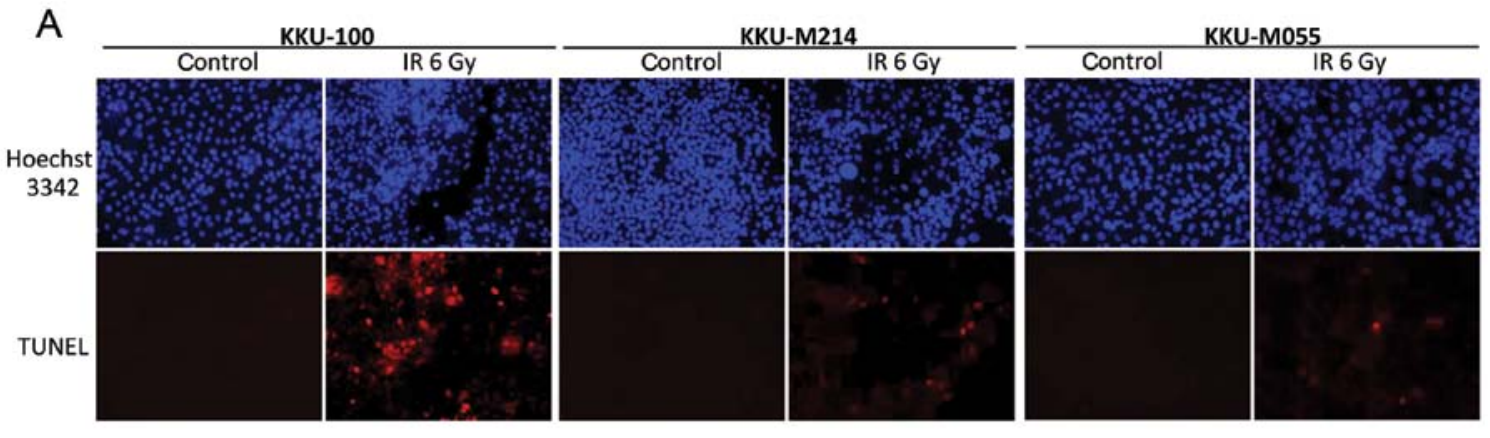

B

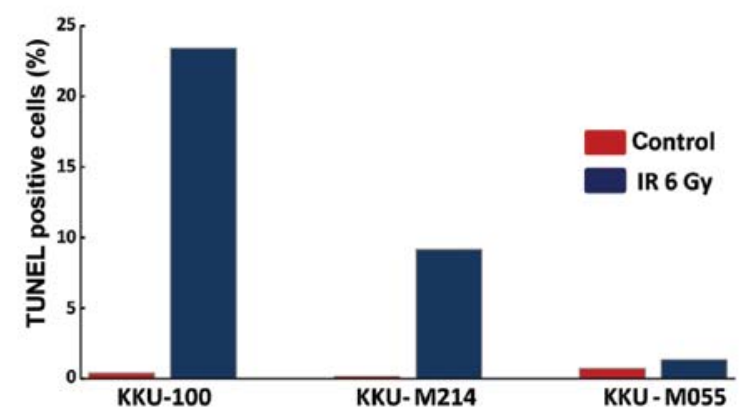

Figure 3. Apoptosis induction in human cholangiocarcinoma cells in response to radiation. The human cholangiocarcinoma cells, KKU-100, KKU-M214 and KKU-M055, were gamma-irradiated with a single dose of 6 Gy. Forty-eight hours after irradiation, TUNEL imaging was performed to detect apoptotic DNA fragments (red). Nuclei were stained with Hoechst 33342 (blue). (A) Representative fluorescence microscopic images of control cells that received no irradiation (control) or 6 Gy gamma-irradiation (IR 6 Gy). (B) Percentages of TUNEL-positive cells counted from 30 fields are shown.

A

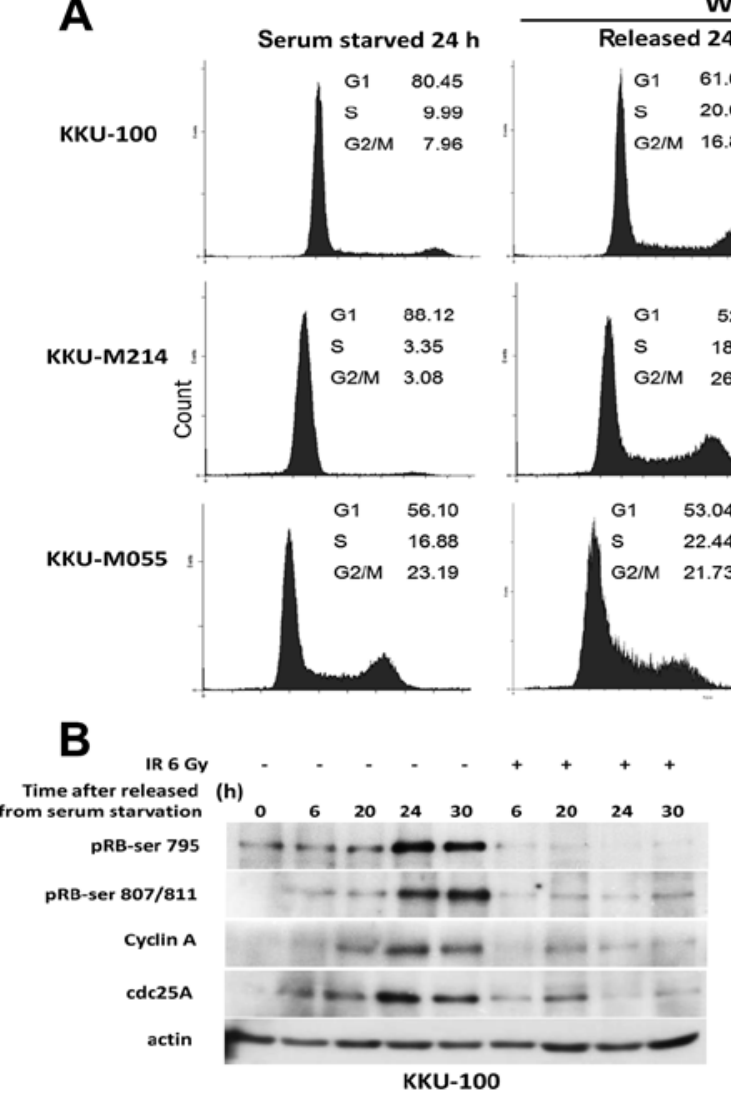

Without IR
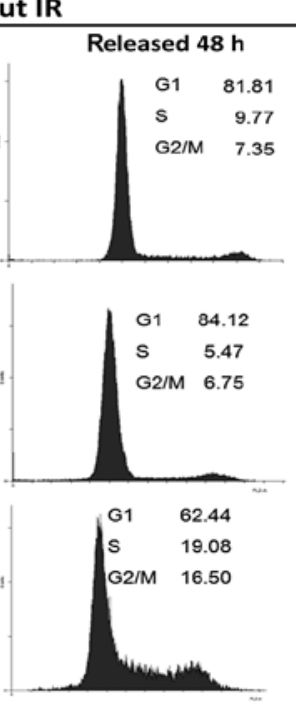

DNA content
With IR 6Gy

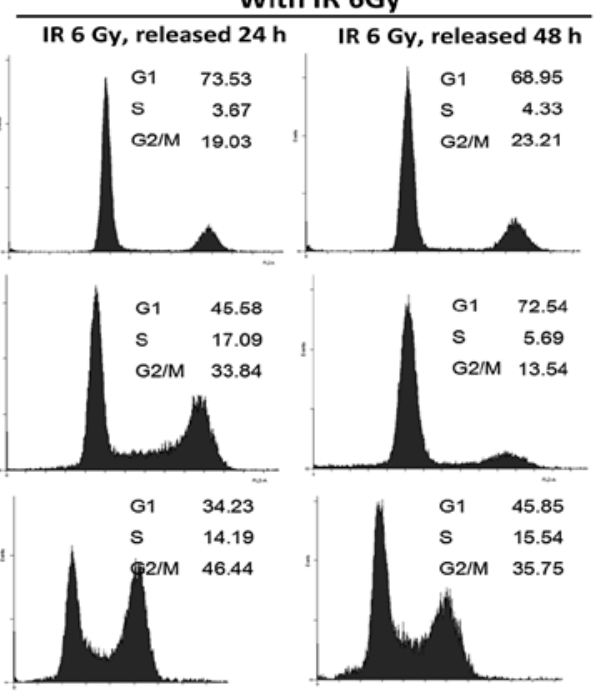

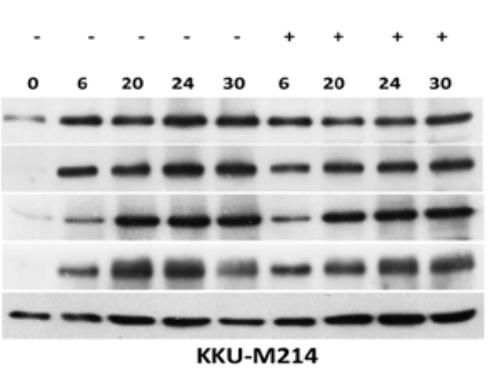

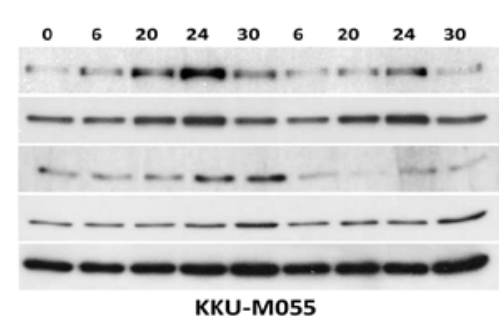

Figure 4. G1 checkpoint status of human cholangiocarcinoma cells in response to radiation damage. The human cholangiocarcinoma cells were cultivated under serum deprivation for $24 \mathrm{~h}$ and then gamma-irradiated with a single dose of $6 \mathrm{~Gy}$. Subsequently, the irradiated cells were released from starvation and collected at different time points for cell cycle and western blot analysis. (A) Cell cycle distribution profiles of KKU-100, KKU-M214 and KKU-M055 cells analyzed by flow cytometry. This result is representative of two independent experiments. (B) Levels of p-RB-Ser795, p-RB-Ser807/811, cyclin A and cdc25A in KKU-100, KKU-M214 and KKU-M055 cells that were treated with (+) or without (-) 6 Gy gamma-irradiation. Detection of actin was used as a loading control. Each result is representative of two independent experiments. 

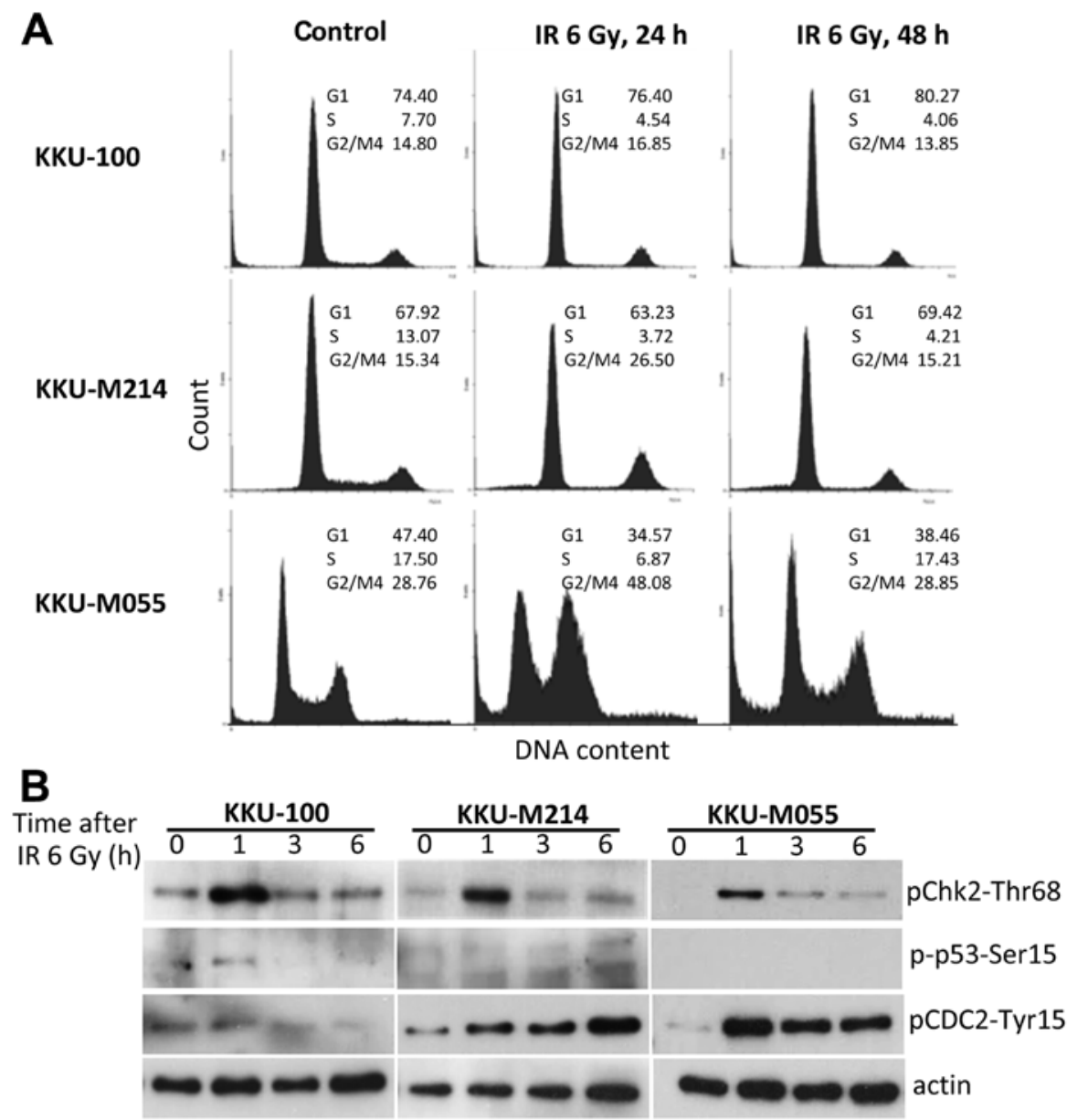

Figure 5. G2 checkpoint status of human cholangiocarcinoma cells in response to radiation damage. The human cholangiocarcinoma cells were gamma-irradiated with a single dose of $6 \mathrm{~Gy}$. Subsequently, the irradiated cells were collected at different time points for cell cycle and western blot analysis. (A) Cell cycle distribution profiles of KKU-100, KKU-M214 and KKU-M055 cells analyzed by flow cytometry. This result is representative of two independent experiments. (B) Levels of p-Chk2-Thr68, p-p53-Ser15 and p-Cdc2-Tyr15 in extracts of KKU-100, KKU-M214 and KKU-M055 cells that were treated with (+) or without (-) 6 Gy gamma-irradiation. Detection of actin was used as a loading control. Each result is representative of two independent experiments.

serum starvation. This finding indicated no progression of KKU-100 cells from $\mathrm{G} 1$ to $\mathrm{S}$ phase in response to radiationinduced damage. In contrast, induction of pRb-Ser795 and pRb-Ser807/811 was observed in irradiated KKU-M214 and KKU-M055 cells. In addition, cdc25A, and cyclin A were increased with time after irradiation in KKU-M214 cells. From these results, it can be assumed that KKU-M214 and KKU-M055 cells were not halted at G/S phase in response to radiation-induced damage.

Transient activation of the $G 2$ checkpoint in radioresistant CCA cells. To investigate the efficiency of the G2 checkpoint of CCA cells, cell cycle and protein levels of phospho-p53, phospho-Chk2 kinase and phospho-Cdc2 kinase were analyzed. Cell cycle distributions were analyzed 24 and $48 \mathrm{~h}$ after irradiation (Fig. 5A). A radiation-induced G2/M block was clearly demonstrated in KKU-M055 cells by an increase of the G2/M population from 29 to $48 \%$ at $24 \mathrm{~h}$ after irradiation. However, the G2/M population of KKU-M055 cells decreased to base line level within $48 \mathrm{~h}$ as compared to that of unirradiated control cells. The G2/M population of KKU-M214 cells was moderately increased from 15 to $27 \%$ at $24 \mathrm{~h}$ after irradiation and decreased to $15 \%$ within $48 \mathrm{~h}$ after irradiation. These results indicate that the G2 checkpoints of KKU-M055 and KKU-M214 cells were transiently activated but cells failed to prolong the G2 arrest after gamma-irradiation. Remarkably, no activation of the G2 checkpoint was found in KKU-100 cells. These findings are consistent with the rapid induction of phospho-Chk2 and phospho-Cdc2 without induction of phospho-p53 in response to radiation damage in KKU-M055 and KKU-M214 cells. In KKU-100 cells, only phospho-Chk2 levels were strongly increased after irradiation, while phospho-Cdc2 and phosphop53 were slightly elevated (Fig. 5B).

Chk1/2 inhibitor enhances the radiosensitivity of radioresistant CCA cells. The inhibition of Chk1 and Chk2 has been reported to enhance the radiosensitivity of several cancer cell lines. Therefore, the potential of Chk1/2 inhibitor (AZD7762) to enhance radiosensitivity of CCA cells was investigated. In all three cell lines, AZD7762 treatment significantly impacted cellular radiosensitivity (Fig. 6A and Table I). Treatment of the cells with AZD7762 significantly enhanced radiosensitivity of KKU-M055 and KKU-M214 cells. The radiation enhancement ratios for KKU-M055 cells, calculated from $\mathrm{D}_{37}$ values are 1.8 and 2.0 for $50 \mathrm{nM}$ and $100 \mathrm{nM}$ AZD7762, respectively. The radiation enhancement 


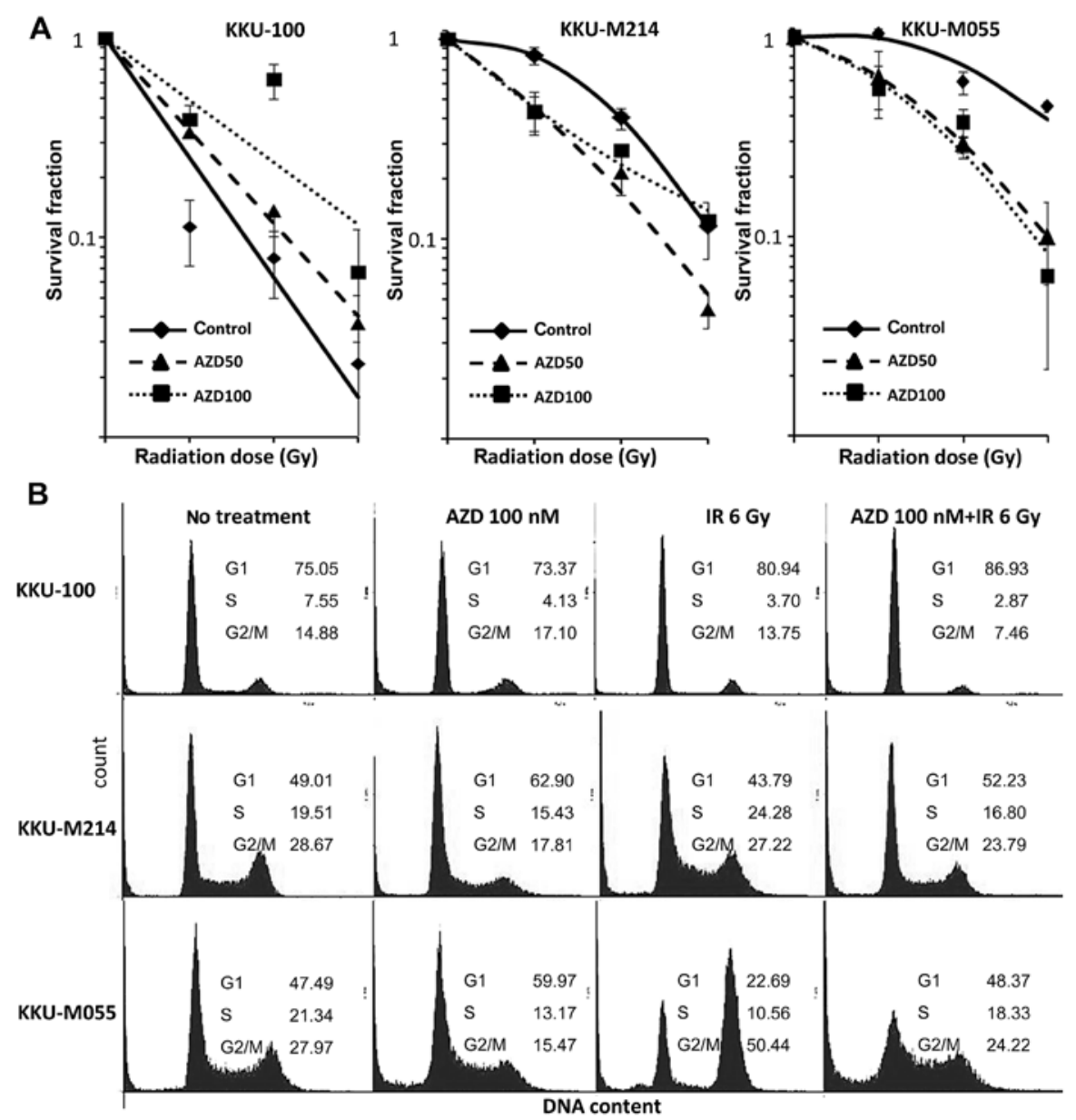

Figure 6. The effect of Chk1/2 inhibitor AZD7762 on the radiosensitivity and the radiation-induced G2 arrest of cholangiocarcinoma cells. (A) Cells were treated with $50 \mathrm{nM}$ of AZD (triangle), $100 \mathrm{nM}$ of AZD (square), or left untreated (control, diamond) for two hours before gamma-irradiation. Clonogenic survival was determined 12 days after gamma-irradiation. The plots show the mean surviving fraction \pm standard deviation of three independent experiments. (B) Cells were seeded into 6-well plates and pre-treated with or without AZD $2 \mathrm{~h}$ before gamma-irradiation. Subsequently, the irradiated cells were collected at different time points for cell cycle analysis. Cell cycle distribution profiles of KKU-100, KKU-M214 and KKU-M055 cells analyzed by flow cytometry. Each result is representative for two independent experiments.

Table I. $\mathrm{D}_{37}$ values observed in different cell lines after AZD7762 treatment.

\begin{tabular}{lrccc}
\hline Cell line & AZD $(\mathrm{nM})$ & $\mathrm{D}_{37}(\mathrm{~Gy}) \pm \mathrm{SD}$ & $\begin{array}{c}\text { p-value } \\
\text { (vs. no AZD treatment) }\end{array}$ & $\begin{array}{c}\text { p-value } \\
\text { (vs. 100 nM AZD treatment) }\end{array}$ \\
\hline KKU-100 & 0 & $1.5 \pm 0.2$ & & \\
KKU-M214 & 50 & $1.9 \pm 0.1$ & 0.338 & $0.034^{\mathrm{b}}$ \\
& 100 & $2.7 \pm 0.5$ & $0.006^{\mathrm{a}}$ & \\
KKU-M055 & 0 & $4.1 \pm 0.2$ & $0.010^{\mathrm{a}}$ & \\
& 50 & $2.4 \pm 0.5$ & $0.015^{\mathrm{a}}$ & \\
& 100 & $2.6 \pm 0.6$ & $0.004^{\mathrm{a}}$ & 0.827 \\
& 0 & $6.1 \pm 0.2$ & $0.002^{\mathrm{a}}$ &
\end{tabular}

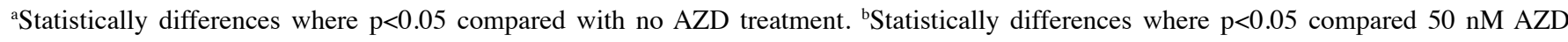
treatment with $100 \mathrm{nM}$ AZD treatment.

ratios for KKU-M214 cells are 1.7 and 1.6 for $50 \mathrm{nM}$ and $100 \mathrm{nM}$ AZD7762, respectively. However, a contradictory effect of AZD7762 on the radiosensitvity of KKU-100 cells was found. AZD7762 treatment significantly reduced radio- 
sensitivity of KKU-100 cells, reflected by an increase of the $\mathrm{D}_{37}$ value from 1.5 to 1.9 and 2.7 for the concentration of 50, and $100 \mathrm{nM} \mathrm{AZD7762,} \mathrm{respectively.} \mathrm{This} \mathrm{result} \mathrm{indicates}$ antagonistic effect of AZD7762 on radiation-induced cell killing in KKU-100 cells.

Chk1/2 inhibitor abrogates radiation-induced G2 arrest of CCA cells. Inhibition of Chk1/2 kinases has been shown to abrogate $\mathrm{G} 2$ checkpoint in response to radiation-induced DNA damage (36). To investigate the effect of AZD7762 on the radiation-induced $\mathrm{G} 2 / \mathrm{M}$ arrest of CCA cells, the cell cycle distribution profiles were analyzed for irradiated cells with or without AZD7762 pretreatment (Fig. 6B).

Radiation-mediated $\mathrm{G} 2$ arrest and abrogation of $\mathrm{G} 2$ arrest by AZD7762 was merely observed in KKU-100 and KKU-M214 cells. By contrast, G2 arrest was strongly induced by radiation treatment in KKU-M055 cells and treatment of the cells with AZD7762 significantly abrogated G2 arrest.

\section{Discussion}

Cellular radiosensitivity is influenced by several factors of DNA damage response and repair processes, cell cycle regulation and cell death pathways $(21,23,24)$. In this study, we demonstrated that three CCA cell lines possessed remarkably different radiosensitivity. The differences were shown partly due to intrinsic factors including the intact p53 and DNA damage checkpoints. Based on this context, KKU-100 cells, shown to be chemotherapeutic resistant (37), were sensitive to radiation. In contrast, chemosensitive cell, KKU-M055, were resistant to irradiation. Moreover, we showed that Chk1/2 inhibitor could abrogate radiation-induced G2 arrest and enhanced radiosensitivity of KKU-M055.

Radiotherapy is regarded as a promising approach to control CCA either as monotherapy or combined with surgical intervention $(9,14,19)$. Although most studies have demonstrated a survival benefit of radiotherapy, the effectiveness of this treatment modality remains very low due to the resistance of CCA cells to the fatal effects of radiation $(15,19,20,38)$. The variation of the radiation responsiveness of individual cancer cells is a key factor that influences radiation treatment outcome $(22,39,40)$. In this study, we demonstrated that the radiosensitivity of CCA cell linesKKU-100, KKU-M214 and KKU-M055 was considerably different, with $\mathrm{D}_{37}$ values of $1.5 \mathrm{~Gy}$ of the most radiosensitive cells (KKU-100) versus 6.1 Gy of the most radioresistant cells (KKU-M055). Interestingly, among three CCA cell lines, KKU-100 has been reported to be the most resistant cell line towards chemotherapeutic drugs (37). Therefore, it would be possible that radiotherapy could be an effective treatment in chemotherapy resistant CCA.

The p53 tumor suppressor protein plays an important role in the regulation of the above described processes (41). It has been reported that cells containing wild-type p53 are more sensitive to radiation than mutant p53-expressing cells (42). In this study, an accumulation of $\mathrm{p} 53$ protein following radiationinduced DNA damage was found in all three CCA cell lines. Nevertheless, expression of full length p53 protein was found in KKU-100 cells only, whereas KKU-M055 and KKU-M214 cells expressed truncated p53. Thus, it can be speculated that the different radiosensitivities of the three CCA cell lines may result from alterations of p53 functions in these cells.

Efficiency of DNA damage checkpoints has a major impact on cellular radiosensitivity. However, p53 mediates cellular radiosensitivity only in the G1-phase of the cell cycle (42). We found that KKU-100, the most radiosensitive cell line, expressed full-length p53 and possessed an intact G1 checkpoint. Therefore, radiosensitivity of CCA cells might rely on the function of p53 and the efficiency of the G1 checkpoint. Since various p53 mutations may result in different phenotypes, the impact of p53 and the G1 checkpoint on the radiosensitivity of CCA cells needs to be further investigated.

Evidence of several studies reveals a strong relationship between apoptotic cell death and radiosensitivity of tumors (23). In the present study, radiation is a potent inducer of apoptosis in the most radiosensitive cell line (KKU-100). Conversely, the potential of radiation to induce apoptosis is very weak in the most radioresistant cells (KKU-M055). Therefore, it can be speculated that cell death by apoptosis might determine overall radiosensitivity of CCA cells. Frequently, aberrations in apoptosis are found in cancer cells carrying p53 mutations and result in a radioresistant phenotype (43). In agreement with our findings, KKU-M055 and M214 cells, expressing truncated p53 proteins are more resistant to radiation as compared to KKU-100 cells. However, the role of $\mathrm{p} 53$ and apoptosis for determining the radiosensitivity of CCA cells remains to be further clarified.

Several studies revealed that $\mathrm{Chk} 1 / 2$ inhibition offers significant and selective tumor radiosensitization (29). In this study, a radiosensitization effect of the Chk1/2 inhibitor AZD7762 was found in two CCA cell lines (KKU-M055 and M214). These cells express a truncated p53 protein and are defective in the G1 checkpoint. On the other hand, the Chk1/2 inhibitor AZD7762 treatment failed to enhance radiosensitivity of KKU-100 cells. Since AZD7762 abrogates radiation-induced $\mathrm{G} 2$ arrest in KKU-M055 cells only, it is unlikely that the abrogation of the $\mathrm{G} 2$ checkpoint primarily contributes to AZD7762-mediated radiosensitization of CCA cells. Recently, AZD7762 was reported to radiosensitize p53 mutant breast cancer cells by inhibiting DNA damage repair and promoting radiation-induced apoptosis and mitotic catastrophe (30). Thus, it is possible that the radiosensitization effect of AZD7762 in CCA cells is mediated via DNA damage repair process and/or cell death pathways.

In conclusion, the benefit of radiotherapy in terms of survival outcomes of CCA patients could be improved by technological advancement of radiation therapy delivery and by selecting tumor entities that respond well to this treatment option. Thus, identification of molecular markers for predicting radiation response of this disease is required. In this study, we demonstrated that the variation of radiosensitivity of CCA cells is correlated with their p53 status and existing G1 and/or G2 checkpoint defects. We also demonstrated the potential of checkpoint kinase Chk1/2 inhibition on the enhancement of the radiosensitivity of CCA cells. Thus, this study provides useful information for predicting radiation response and provides evidence for the enhancement of radiotherapeutic efficiency by targeting checkpoint kinase $\mathrm{Chk} 1 / 2$ in some subpopulations of CCA patients. 


\section{Acknowledgements}

This research was supported by Khon Kaen University Research grant and the Higher Education Research Promotion and National Research University Project of Thailand, Office of the Higher Education Commission, through the Health cluster (SHeP-GMS) to S.W. We thank the radiation therapy department, Buddchachinaraj Hospital, Phitsanulok for providing the radiation source.

\section{References}

1. Welzel TM, McGlynn KA, Hsing AW, O'Brien TR and Pfeiffer RM: Impact of classification of hilar cholangiocarcinomas (Klatskin tumors) on the incidence of intra- and extrahepatic cholangiocarcinoma in the United States. J Natl Cancer Inst 98: 873-875, 2006.

2. Luke C, Price T and Roder D: Epidemiology of cancer of the liver and intrahepatic bile ducts in an Australian population. Asian Pac J Cancer Prev 11: 1479-1485, 2010.

3. Khan SA, Taylor-Robinson SD, Toledano MB, Beck A, Elliott P and Thomas HC: Changing international trends in mortality rates for liver, biliary and pancreatic tumours. J Hepatol 37 : 806-813, 2002.

4. Patel T: Worldwide trends in mortality from biliary tract malignancies. BMC Cancer 2: 10, 2002.

5. Patel T: Cholangiocarcinoma - controversies and challenges. Nat Rev Gastroenterol Hepatol 8: 189-200, 2011.

6. Arrington AK, Nelson RA, Falor A, Luu C, et al: Impact of medical and surgical intervention on survival in patients with cholangiocarcinoma. World J Gastrointest Surg 5: 178-186, 2013

7. DeOliveira ML, Cunningham SC, Cameron JL, et al: Cholangiocarcinoma: thirty-one-year experience with 564 patients at a single institution. Ann Surg 245: 755-762, 2007.

8. Hemming AW, Reed AI, Fujita S, Foley DP and Howard RJ: Surgical management of hilar cholangiocarcinoma. Ann Surg 241: 699-702, 2005.

9. Ramirez-Merino N, Aix SP and Cortes-Funes H: Chemotherapy for cholangiocarcinoma: An update. World J Gastrointest Oncol 5: 171-176, 2013.

10. Zografos GN, Farfaras A, Zagouri F, Chrysikos D and Karaliotas K: Cholangiocarcinoma: principles and current trends. Hepatobiliary Pancreat Dis Int 10: 10-20, 2011.

11. Alberts SR, Al-Khatib H, Mahoney MR, et al: Gemcitabine, 5-fluorouracil, and leucovorin in advanced biliary tract and gallbladder carcinoma: a North Central Cancer Treatment Group phase II trial. Cancer 103: 111-118, 2005.

12. Patt YZ, Hassan MM, Aguayo A, et al: Oral capecitabine for the treatment of hepatocellular carcinoma, cholangiocarcinoma, and gallbladder carcinoma. Cancer 101: 578-586, 2004.

13. Woo SM, Lee WJ, Han SS, et al: Capecitabine plus cisplatin as first-line chemotherapy for advanced biliary tract cancer: a retrospective single-center study. Chemotherapy 58: 225-232, 2012.

14. Maithel SK, Gamblin TC, Kamel I, Corona-Villalobos CP, Thomas M and Pawlik TM: Multidisciplinary approaches to intrahepatic cholangiocarcinoma. Cancer 22: 3929-3942, 2013.

15. Barney BM, Olivier KR, Miller RC and Haddock MG: Clinical outcomes and toxicity using stereotactic body radiotherapy (SBRT) for advanced cholangiocarcinoma. Radiat Oncol 7: 67, 2012.

16. Gonzalez Gonzalez D, Gouma DJ, Rauws EA, van Gulik TM, Bosma A and Koedooder C: Role of radiotherapy, in particular intraluminal brachytherapy, in the treatment of proximal bile duct carcinoma. Ann Oncol 10 (Suppl 4): 215-220, 1999.

17. Isayama $H$, Tsujino $T$, Nakai $Y$, et al: Clinical benefit of radiation therapy and metallic stenting for unresectable hilar cholangiocarcinoma. World J Gastroenterol 18: 2364-2370, 2012.

18. McMasters KM, Tuttle TM, Leach SD, Rich T, Cleary KR, Evans DB and Curley SA: Neoadjuvant chemoradiation for extrahepatic cholangiocarcinoma. Am J Surg 174: 605-608, 1997.
19. Brunner TB and Eccles CL: Radiotherapy and chemotherapy as therapeutic strategies in extrahepatic biliary duct carcinoma. Strahlenther Onkol 186: 672-680, 2010.

20. Ghafoori AP, Nelson JW, Willett CG, et al: Radiotherapy in the treatment of patients with unresectable extrahepatic cholangiocarcinoma. Int J Radiat Oncol Biol Phys 81: 654-659, 2011.

21. Mladenov E, Magin S, Soni A and Iliakis G: DNA doublestrand break repair as determinant of cellular radiosensitivity to killing and target in radiation therapy. Front Oncol 3: 113 , 2013.

22. Baumann M, Krause M and Hill R: Exploring the role of cancer stem cells in radioresistance. Nat Rev Cancer 8: 545-554, 2008.

23. Balcer-Kubiczek EK: Apoptosis in radiation therapy: a double-edged sword. Exp Oncol 34: 277-285, 2012.

24. Shimura T: Acquired radioresistance of cancer and the AKT/GSK3beta/cyclin D1 overexpression cycle. J Radiat Res 52: 539-544, 2011.

25. Sancar A, Lindsey-Boltz LA, Unsal-Kacmaz K and Linn S: Molecular mechanisms of mammalian DNA repair and the DNA damage checkpoints. Annu Rev Biochem 73: 39-85, 2004.

26. Schmitt CA: Senescence, apoptosis and therapy - cutting the lifelines of cancer. Nat Rev Cancer 3: 286-295, 2003.

27. Kawabe T: G2 checkpoint abrogators as anticancer drugs. Mol Cancer Ther 3: 513-519, 2004.

28. Bucher N and Britten CD: G2 checkpoint abrogation and checkpoint kinase-1 targeting in the treatment of cancer. Br J Cancer 98: 523-528, 2008.

29. Lapenna S and Giordano A: Cell cycle kinases as therapeutic targets for cancer. Nat Rev Drug Discov 8: 547-566, 2009.

30. Ma Z, Yao G, Zhou B, Fan Y, Gao S and Feng X: The Chk1 inhibitor AZD7762 sensitises p53 mutant breast cancer cells to radiation in vitro and in vivo. Mol Med Rep 6: 897-903, 2012.

31. Riesterer O, Matsumoto F and Wang L: A novel Chk inhibitor, XL-844, increases human cancer cell radiosensitivity through promotion of mitotic catastrophe. Invest New Drugs 29: 514-522, 2011

32. Tandle AT, Kramp T, Kil WJ, et al: Inhibition of polo-like kinase 1 in glioblastoma multiforme induces mitotic catastrophe and enhances radiosensitisation. Eur J Cancer 49: 3020-3028, 2013.

33. Tang Y, Dai Y, Grant S and Dent P: Enhancing CHK1 inhibitor lethality in glioblastoma. Cancer Biol Ther 13: 379-388, 2012.

34. Maruyama M, Kobayashi N, Westerman KA, et al: Establishment of a highly differentiated immortalized human cholangiocyte cell line with SV40T and hTERT. Transplantation 77: 446-451, 2004.

35. Hematulin A, Sagan D, Eckardt-Schupp F and Moertl S: NBS1 is required for IGF-1 induced cellular proliferation through the Ras/Raf/MEK/ERK cascade. Cell Signal 20: 2276-2285, 2008.

36. Morgan MA, Parsels LA, Zhao L, et al: Mechanism of radiosensitization by the Chk1/2 inhibitor AZD7762 involves abrogation of the $\mathrm{G} 2$ checkpoint and inhibition of homologous recombinational DNA repair. Cancer Res 70: 4972-4981, 2010.

37. Tepsiri N, Chaturat L, Sripa B, Namwat W, Wongkham S, Bhudhisawasdi V and Tassaneeyakul W: Drug sensitivity and drug resistance profiles of human intrahepatic cholangiocarcinoma cell lines. World J Gastroenterol 11: 2748-2753, 2005.

38. Deodato F, Clemente G, Mattiucci GC, et al: Chemoradiation and brachytherapy in biliary tract carcinoma: long-term results. Int J Radiat Oncol Biol Phys 64: 483-488, 2006.

39. Bonkhoff H: Factors implicated in radiation therapy failure and radiosensitization of prostate cancer. Prostate Cancer 2012: 593241,2012

40. Coventry BJ and Ashdown ML: Complete clinical responses to cancer therapy caused by multiple divergent approaches: a repeating theme lost in translation. Cancer Manag Res 4: 137-149, 2012.

41. Fei P and El-Deiry WS: P53 and radiation responses. Oncogene 22: $5774-5783,2003$

42. Mazzatti DJ, Lee YJ, Helt CE, O'Reilly MA and Keng PC: p53 modulates radiation sensitivity independent of p21 transcriptional activation. Am J Clin Oncol 28: 43-50, 2005.

43. Lu C and El-Deiry WS: Targeting p53 for enhanced radio- and chemo-sensitivity. Apoptosis 14: 597-606, 2009. 